\title{
Precipitation in stretched Al-Cu-Mg alloys with reduced alloying content studied by DSC, TEM and atom probe
}

\author{
N. Gao, L. Davin ${ }^{1}$, S. Wang, A. Cerezo ${ }^{1}$ and M.J. Starink \\ Materials Research Group, School of Engineering Sciences, University of Southampton, \\ Southampton, SO17 1BJ \\ ${ }^{1}$ Department of Materials, University of Oxford, Parks Road, Oxford OX1 3PH, UK
}

Keywords: $\mathrm{DSC}$, atom probe, precipitation, $\mathrm{Al}-\mathrm{Cu}-\mathrm{Mg}$ alloys, GPB zone

\begin{abstract}
The hardening and microstructural evolution during ageing of a $\mathrm{Al}-1.2 \mathrm{Cu}-0.5 \mathrm{Mg}$ and a Al-1.2Cu-1.2Mg (at.\%) alloy has been investigated. Artificial ageing at $150^{\circ} \mathrm{C}$ of stretched and naturally aged samples initially (up to about $48 \mathrm{~h}$ ) leads to very limited further strengthening, but ageing at $190^{\circ} \mathrm{C}$ results a quick increase in strength. Detailed microstructural investigation using differential scanning calorimetry, transmission electron microscopy and three-dimensional atom probe demonstrated that hardening at $150^{\circ} \mathrm{C}$ is mostly dominated by the formation of solute clusters with varying compositions and plate-like zones rich in copper at early stages of ageing $(\mathrm{t}<24 \mathrm{~h})$ and by the formation of $\mathrm{S}$ phase at the later stages of ageing. At higher $190^{\circ} \mathrm{C}$ no zones or clusters form and the ageing is dominated by the formation of $\mathrm{S}$ precipitates.
\end{abstract}

\section{Introduction}

The Al-Cu-Mg alloys are capable of developing medium-high strength and retaining their strength at relatively high temperatures. It has been found that hardening occurs in two distinct stages in Al$\mathrm{Cu}-\mathrm{Mg}$ alloys [1]. For a long time, it has been generally accepted that the origin of the first stage of rapid hardening is related to GPB zone formation and the second stage is attributed to the precipitation of the S' / S phase [2]. However controversy exists, especially relating to the existence of a $S "$ phase and the nature of the precipitation responsible for the first stage of hardening $[3,4,5]$.

It has been noted that the majority of research on early-stage precipitation in Al-Cu-Mg alloys so far has been focused on alloys either at T4 (solution treated and naturally aged) or at T6 (solution treated and artificially aged) condition. However, stretching after quenching, which is common for commercial applications, will have a profound influence on the precipitation and properties of the alloys. Little detailed work on precipitation in these stretched and aged materials has been reported. This paper combines the use of hardness measurement (HV), differential scanning calorimetry (DSC), transmission electron microscopy (TEM) and 3-dimensional atom probe (3DAP) techniques to provide a comprehensive insight into the precipitation behaviour of two $\mathrm{Al}-\mathrm{Cu}-\mathrm{Mg}$ alloys with reduced alloying content (compared to standard 2024 and 2018 type alloys), which have been quenched, stretched and subsequently artificially aged. The aim is to explain the relation between precipitation and strength for these alloys.

\section{Experimental Procedures}

Two Al-Cu-Mg alloys with a $\mathrm{Cu} / \mathrm{Mg}$ ratio of 2.3 and 1.0 (at\% ratio) have been manufactured and studied (Table 1). Details on production route for the alloys are given in the companion paper [6]. After solution treatment (Alloy 1 at $525^{\circ} \mathrm{C}$ and Alloy 2 at $495^{\circ} \mathrm{C}$ ), water quenching and stretching by $2.5 \%$, the alloys have been left at room temperature for a few months before further ageing for $12-72 \mathrm{~h}$ at $150^{\circ} \mathrm{C}$ and for $6-48 \mathrm{~h}$ at $190^{\circ} \mathrm{C}$ respectively. Vickers hardness values were obtained from surfaces ground with \#1200 grade $\mathrm{SiC}$ paper. Four indentations were made on each specimen with a $20 \mathrm{~kg}$ load and a mean HV is given. The DSC experiments were conducted using a Perkin-Elmer 
Pyris 1 in nitrogen atmosphere at a constant heating rate of $10^{\circ} \mathrm{C} / \mathrm{min}$, using disc-shaped DSC samples with a thickness about $0.9 \mathrm{~mm}$ and diameter $5 \mathrm{~mm}$. All runs were corrected by subtracting the baseline of the DSC, which was obtained from a run with an empty pan as reference. Experimental details of the TEM work are given elsewhere [7]. All observations were performed in the $\langle 100\rangle$ matrix orientation. The 3DAP analyses were conducted on an energy-compensated optical position sensitive atom probe [4]. The specimens (in the shape of sharp needles with an end radius less than $100 \mathrm{~nm}$ ) were prepared by a two-stage electropolishing method. Analyses were carried out

at $15 \mathrm{~K}$ with a pulse fraction (ratio of the pulse voltage to the direct current standing voltage) of $20 \%$ and a pulse repetition rate of $1500 \mathrm{~Hz}$. The voltage was between 4.5 and $9.5 \mathrm{kV}$ depending on the analysis.

\begin{tabular}{|c|c|c|c|}
\hline Alloy & $\mathrm{Cu}$ & $\mathrm{Mg}$ & $\mathrm{Mn}$ \\
\hline Alloy 1 & 1.18 & 0.51 & 0.21 \\
\hline Alloy 2 & 1.21 & 1.19 & 0.20 \\
\hline
\end{tabular}

Table 1: Compositions of the alloys

\section{Experimental Results}

Vickers hardness and DSC analysis In quenched state hardness values are 63 for Alloy 1 and 72 for Alloy 2 [8]. Fig. 1 shows the hardness for stretched and stretched and aged conditions for both alloys. At $150^{\circ} \mathrm{C}$ hardness increases slowly with ageing time and only shows an obvious increase after $48 \mathrm{hrs}$. At $190^{\circ} \mathrm{C}$ the hardness rapidly increases at first and then gradually decreases.

Figs. 2 and 3 present the DSC results for both alloys aged at $150^{\circ} \mathrm{C}$. Four effects (two exothermic and two endothermic) are evident. In line with results from literature $[9,10]$, the dissolution of GPB zones and/or clusters occurs at $100-230^{\circ} \mathrm{C}$ and $\mathrm{S}$

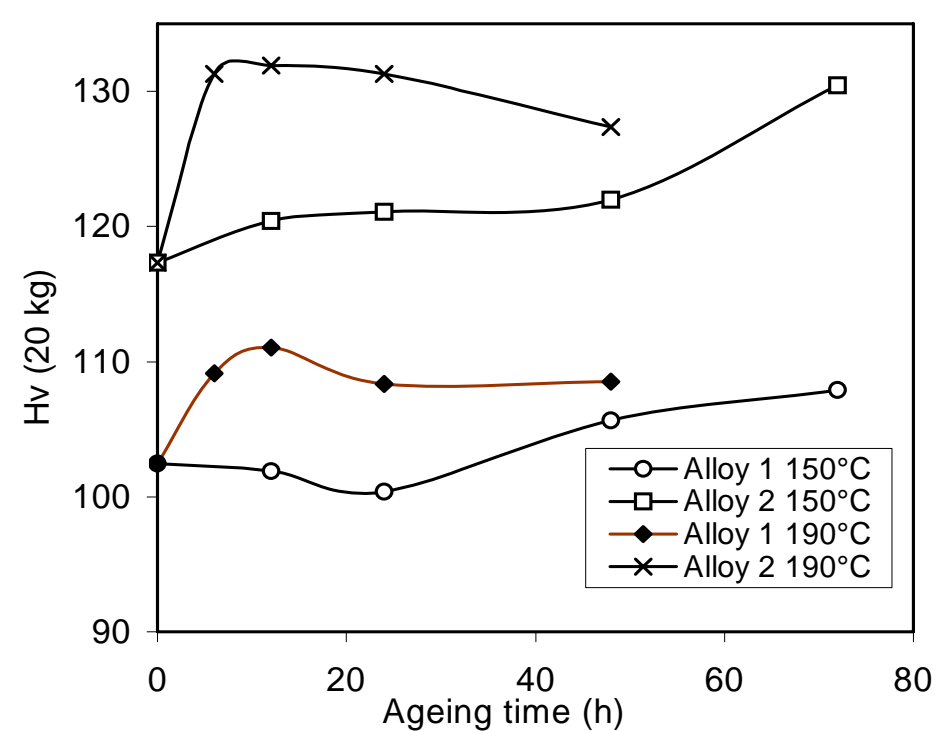

Fig. 1: Vickers hardness for both alloys aged at 150 and $190^{\circ} \mathrm{C}$

formation occurs at $230-320^{\circ} \mathrm{C}$ with a peak at about $270^{\circ} \mathrm{C}$. The $\mathrm{S}$ dissolution is in the range of 330$470^{\circ} \mathrm{C}$. The DSC curves reveal that the magnitude of the S precipitation effect in Alloy 1 is less than half that of Alloy 2. This is due to the limited $\mathrm{Mg}$ content in Alloy 1 . Alloy 2 with a low $\mathrm{Cu} / \mathrm{Mg}$ ratio only precipitates $\mathrm{S}$ phase; but Alloy 1 with a high $\mathrm{Cu} / \mathrm{Mg}$ ratio appears to show a second precipitation effect (at about $390^{\circ} \mathrm{C}$ ) which thought to be caused by $\theta$ or $\Omega$ formation. For ageing at $150^{\circ} \mathrm{C}$, the heat content of $\mathrm{S}$ formation peaks decreases with increase of ageing time from 12 to 72 hours. From the reductions it is clear that substantial S precipitation occurs especially after $24 \mathrm{~h}$ ageing. Figs. 2 and 3 further show that at $150^{\circ} \mathrm{C}$ initially zones form, which are later gradually replaced by $\mathrm{S}$ phase. During $190^{\circ} \mathrm{C}$ ageing for Alloys 1 and 2, no zones form (effect at $100-230^{\circ} \mathrm{C}$ vanishes) and only $\mathrm{S}$ formation occurs (Figs. 4). At $6 \mathrm{~h}$ ageing there is still a small $\mathrm{S}$ formation peak, but with further ageing, the $\mathrm{S}$ precipitation peak completely disappears. This means that on isothermal ageing at $190^{\circ} \mathrm{C}$ most of the $\mathrm{S}$ formation is completed within about $6 \mathrm{~h}$. For the solutiontreated and natural aged Alloy 1, the zones/clusters dissolution effect occurs in two stages with the first stage being completed at about $160^{\circ} \mathrm{C}$ (Fig. 2). Ageing at $150^{\circ} \mathrm{C}$ causes this first stage to disappear. 


\section{TEM analysis}

At $150^{\circ} \mathrm{C} / 12 \mathrm{~h}$, TEM reveals many dislocation lines and loops for both alloys. The dislocations result from the stretching after solution treatment and the loops are generally caused by condensation of quenched in vacancies. No precipitates were observed in bright field (BF) and no extra diffraction spots except the aluminium matrix could be resolved from the $[001]_{\mathrm{Al}}$ zone. When the ageing time was increased to $24 \mathrm{~h}$, dislocations still dominate the structure. Only from $150^{\circ} \mathrm{C} / 48 \mathrm{~h}$ or longer ageing, could $\mathrm{S}$ precipitation be found, initially by dark field (DF) images and selected-area diffraction patterns (SADP). Zones/clusters could not be detected probably due to their sizes being below the detection limit of the conventional TEM. At $190^{\circ} \mathrm{C} / 12 \mathrm{~h}$, there are many $\mathrm{S}$ precipitates in the form of needles or laths in the matrix (Fig. 5), as well as some coarse ones located on grain boundaries. Analysis of diffraction patterns indicates that there only $\mathrm{S}$ phase is present in Alloy 2. Most precipitates are S phase in Alloy 1 , but a few diffraction patterns reveal evidence of $\Omega$ precipitates (Fig. 5(b)). No $\theta$ was found by SADP in either alloy. Some $\mathrm{S}$ phase precipitates form as loop-like structures, which were apparently inherited from the shapes of original dislocation loops.

3DAP analysis

Analyses have been performed by $3 \mathrm{DAP}$ on both alloys aged at $150^{\circ} \mathrm{C} / 12$ h. Fig 6 a shows an example of atom map from the

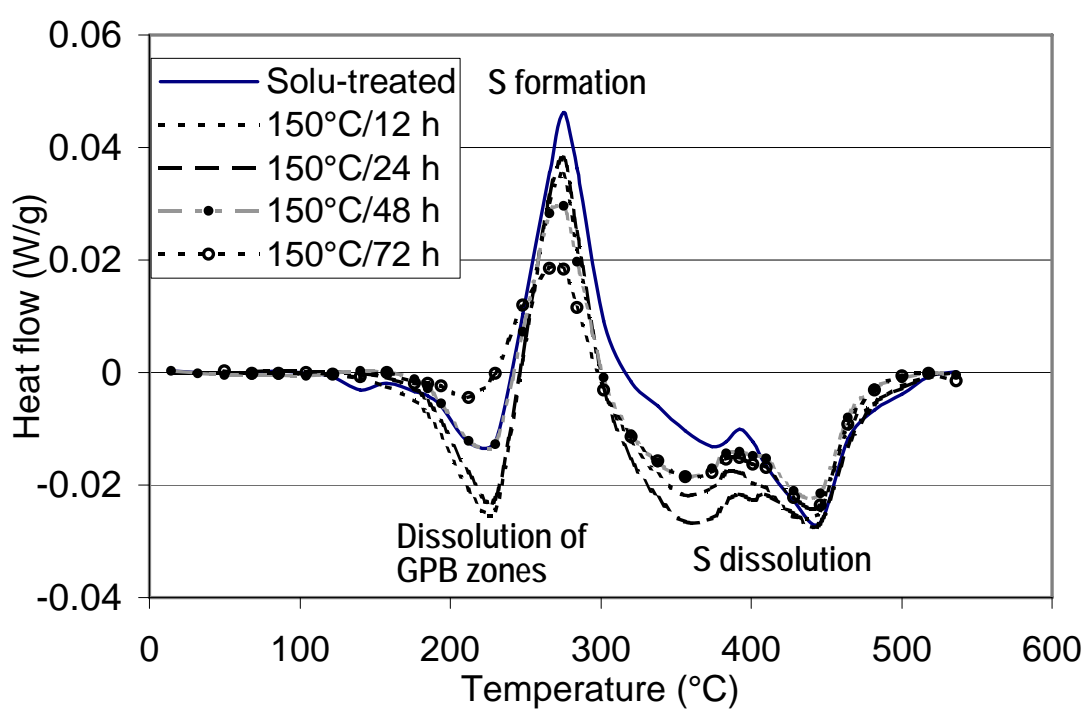

Fig. 2 DSC curves of Alloy 1 aged at $150^{\circ} \mathrm{C}$.

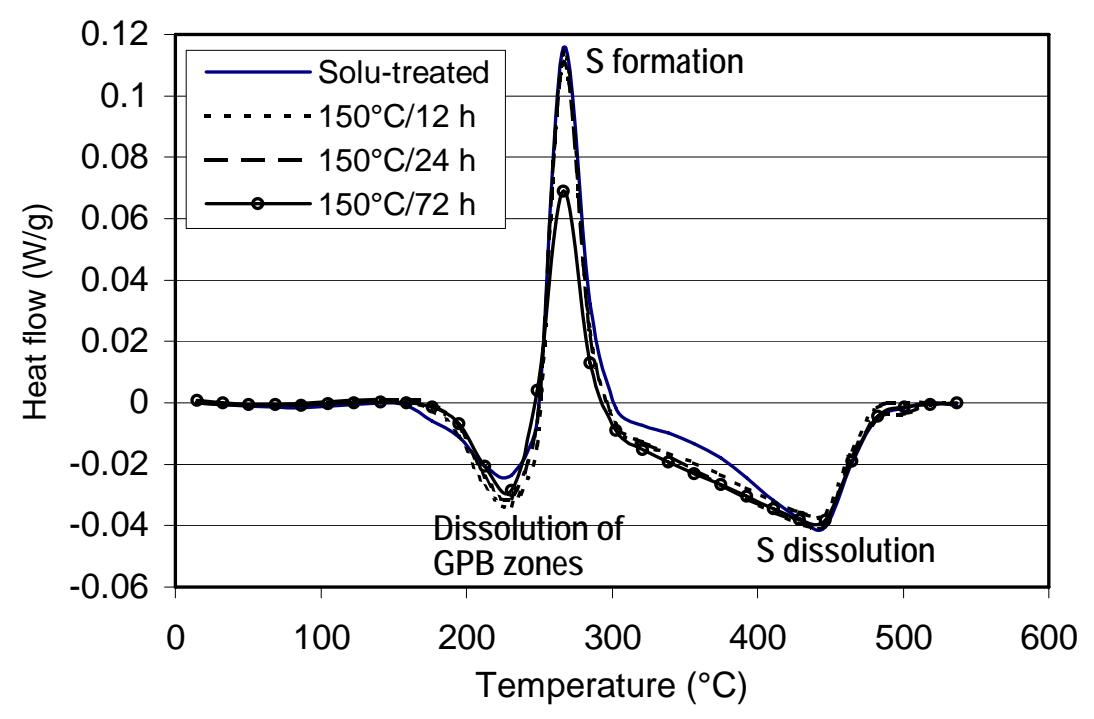

Fig. 3 DSC curves of Alloy 2 aged at $150^{\circ} \mathrm{C}$.

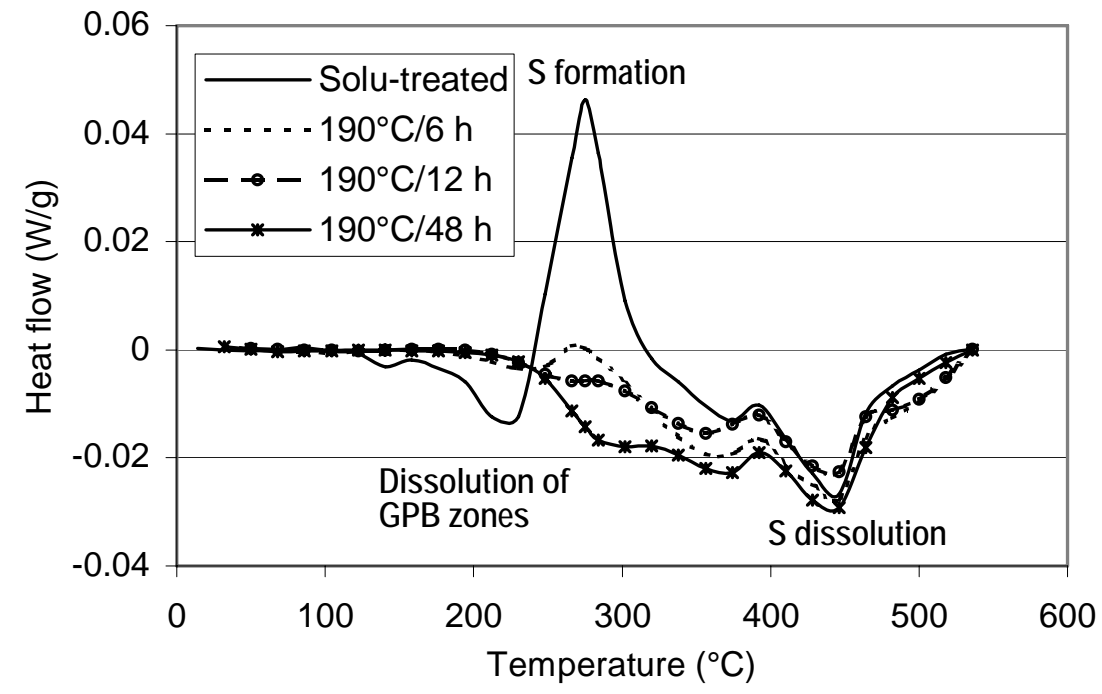

Fig. 4 DSC curves of Alloy 1 aged at $190^{\circ} \mathrm{C}$. 
Fig. 5 TEM micrographs of

precipitation. (a-b) S and $\Omega$ precipitates in Alloy 1; (c-d) S phase in Alloy 2, all aged for 12
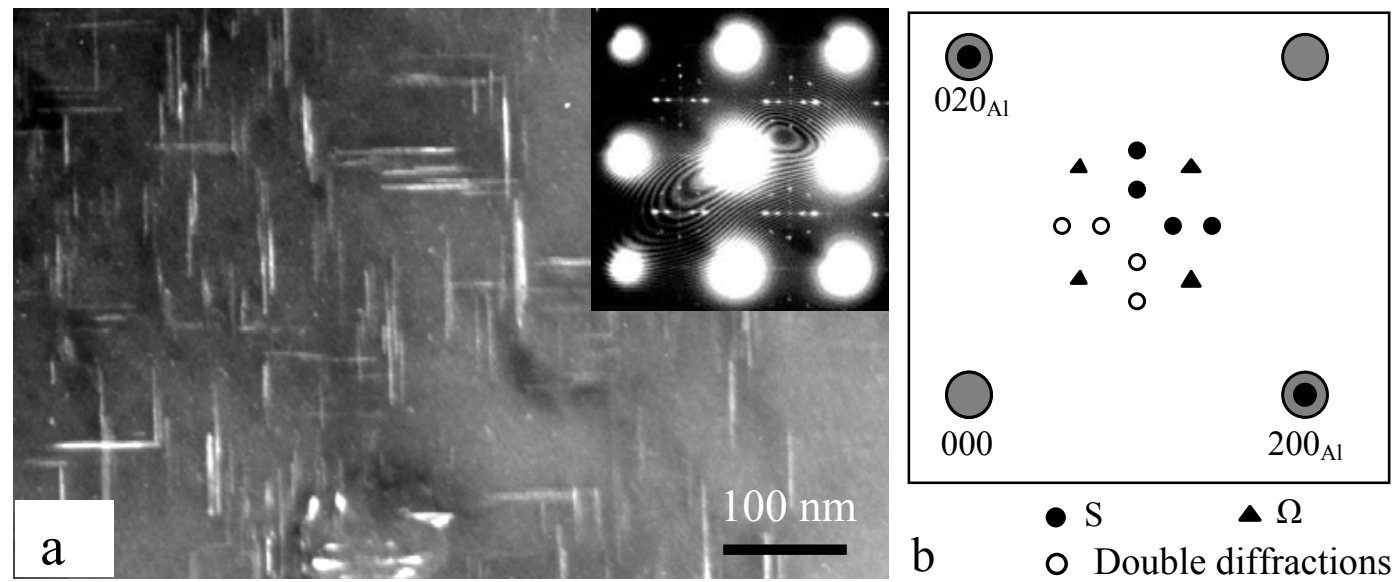

h at $190^{\circ} \mathrm{C}$ (dark field, $\mathrm{B}=[001])$.
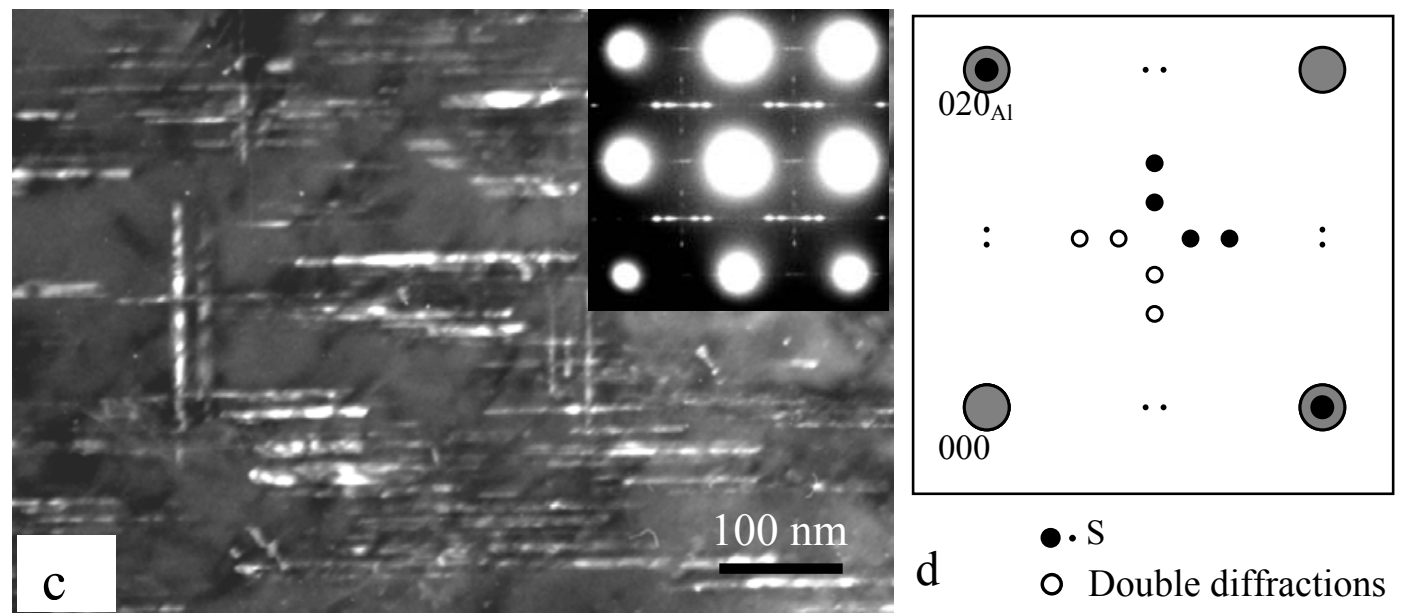

3DAP analysis of alloy 1 showing the distribution of the alloying elements. Analytical software developed by Vaumousse et al [11] has been employed to analyse the clusters in the alloys. The selection of solute-rich regions is performed by connecting solute atoms (in our case $\mathrm{Cu}$ and $\mathrm{Mg}$ ), which lie within a fixed distance $(d)$, and eliminating clusters containing less than a minimum of solute atoms $\left(N_{\min }\right)$. Other atoms within some distance $L$ greater than $d$ are then taken to belong to the same cluster. The value of $d$ and $L$ have been selected as 0.6 and 0.8 . The value of $N_{\min }$ varies from 8 to 14 atoms of $\mathrm{Mg}$ and $\mathrm{Cu}$. Fig $6 \mathrm{~b}$ shows all the microstructural features (clusters and different types of precipitates) detected on the 3DAP analysis of fig 6a using this software. 3DAP analysis of a number of specimens show that there are more $\mathrm{Mg} / \mathrm{Cu}$ clusters in Alloy 2 than in Alloy 1. Table 2 shows the compositions of six of the largest clusters containing more than 10 (in Alloy 1) and 14 (in Alloy 2) atoms of $\mathrm{Mg}$ and $\mathrm{Cu}$, in which the A stands for the total composition of the clusters and B stands for the solute atom composition of the clusters. From this Table, it can be seen that most of the clusters contain more than $90 \%$ of aluminium. The contents of $\mathrm{Mg}$ and $\mathrm{Cu}$ are in the range of $0.9-4.2$ and 1.7-5.2. The $\mathrm{Mg} / \mathrm{Cu}$ ratio is found to vary from one cluster to another and in most cases they are richer in $\mathrm{Cu}$ than $\mathrm{Mg}$.

\begin{tabular}{|l|c|c|c|c|c|c|c|c|c|c|c|c|}
\hline & \multicolumn{9}{|c|}{ Alloy 1 } & \multicolumn{9}{c|}{ Alloy 2 } \\
\hline & \multicolumn{2}{|c|}{ Cluster 1 } & \multicolumn{2}{c|}{ Cluster 2 } & \multicolumn{2}{c|}{ Cluster 3 } & \multicolumn{2}{c|}{ Cluster 1 } & \multicolumn{2}{c|}{ Cluster 2 } & \multicolumn{2}{c|}{ Cluster 3 } \\
\hline & \multicolumn{2}{|c|}{1280} & \multicolumn{2}{|c|}{404} & \multicolumn{2}{|c|}{240} & \multicolumn{2}{c|}{260} & \multicolumn{2}{c|}{631} & \multicolumn{2}{c|}{601} \\
\hline No of atoms & $\mathrm{A}$ & $\mathrm{B}$ & $\mathrm{A}$ & $\mathrm{B}$ & $\mathrm{A}$ & $\mathrm{B}$ & $\mathrm{A}$ & $\mathrm{B}$ & $\mathrm{A}$ & $\mathrm{B}$ & $\mathrm{A}$ & $\mathrm{B}$ \\
\hline & 96.4 & - & 93.6 & - & 93.3 & - & 93 & - & 96.5 & - & 94 & - \\
\hline $\mathrm{Al} \%$ & 0.9 & 26.1 & 1.2 & 19.2 & 4.2 & 62.5 & 1.9 & 28 & 1.3 & 37 & 2.5 & 43 \\
\hline $\mathrm{Mg} \%$ & 2.5 & 69.6 & 5.2 & 80.8 & 1.7 & 25 & 4.6 & 67 & 2.2 & 63 & 3 & 51 \\
\hline $\mathrm{Cu} \%$ & 0.16 & 4.4 & 0 & 0 & 0.8 & 12.5 & 0.4 & 5 & 0 & 0 & 0.3 & 0 \\
\hline $\mathrm{Mn} \%$ & &
\end{tabular}

Table 2: The composition of $\mathrm{Mg} / \mathrm{Cu}$ clusters in both alloys

3DAP further revealed small plate-like precipitates/zones rich in copper in both alloys. Their diameter is about $6 \mathrm{~nm}$, and compositions are about $90.7 \% \mathrm{Al}, 1.3 \% \mathrm{Mg}, 8 \% \mathrm{Cu}$. Charai et al. [12] 
referred to similarly shaped (pre-)precipitates of similar size in T6 type material as GPB zones. However our plates appear larger than a monolayer in thickness and pure copper whereas Charai et al observed a significant $\mathrm{Mg}$ level. Some small rod like $\mathrm{Cu} / \mathrm{Mg}$ rich precipitates have also been found . From their analysed compositions $(95 \% \mathrm{Al}, 2.6 \mathrm{Cu}, 2.2 \mathrm{Mg}$ for Alloy 1 and $94 \% \mathrm{Al}, 2.5 \mathrm{Cu}$, $3.3 \mathrm{Mg}$ for Alloy 2), it is expected that they are probably $\mathrm{S}$ phase $\left(\mathrm{Al}_{2} \mathrm{CuMg}\right)$ since the $\mathrm{Cu}$ and $\mathrm{Mg}$ contents are approximately equal.

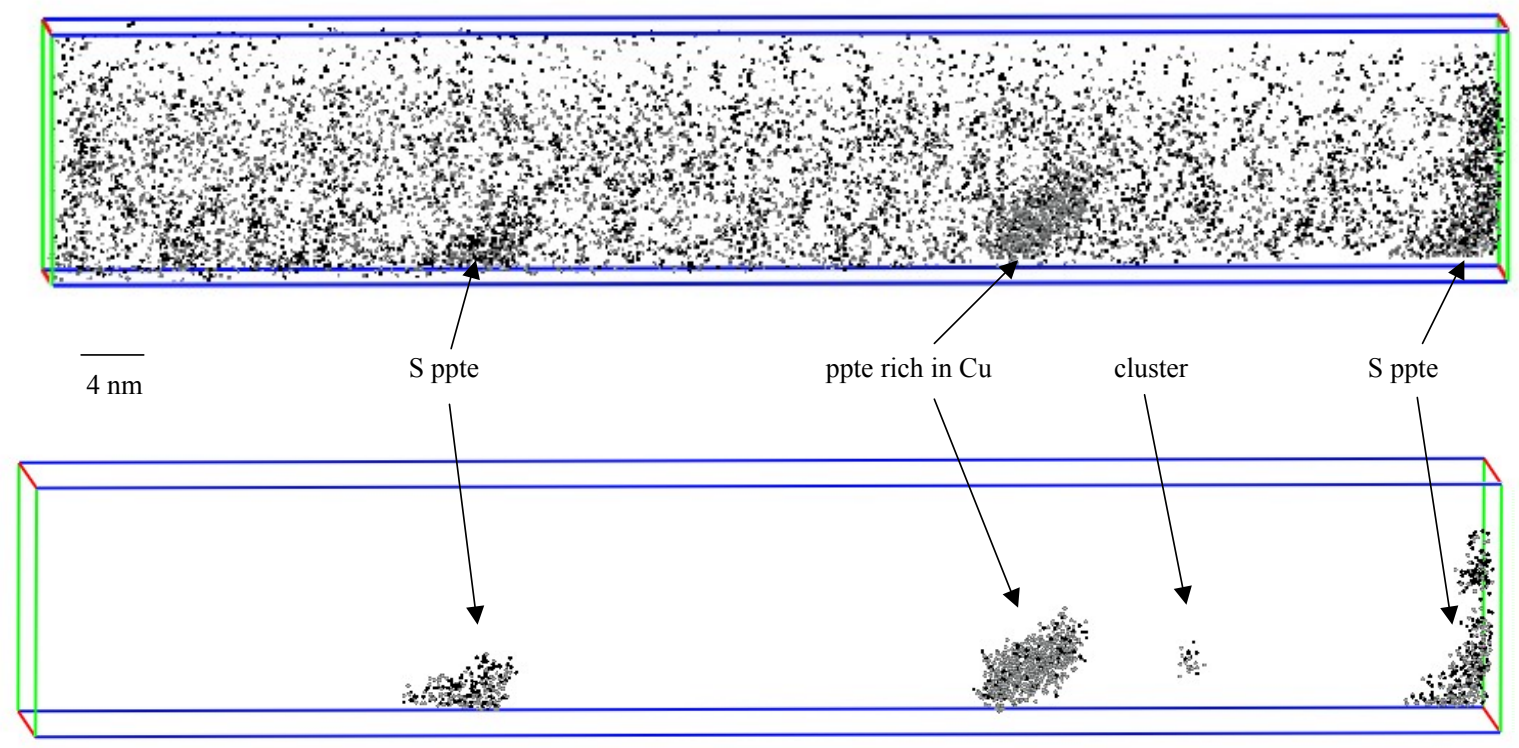

Fig. 6. Atom maps of the alloy 1 heat treated at $150^{\circ} \mathrm{C}$ for $12 \mathrm{~h}$ : complete map (a) before extraction of cluster/precipitates (ppte) formed by more than 10 atoms of Copper and Magnesium (b)

\section{Discussion}

Altogether, the experimental results have allowed the precipitation sequence to be defined in both alloys 1 and 2 heat treated at $150^{\circ} \mathrm{C}$. In alloy 1 , clusters, zones and $\mathrm{S}$ phase were found, the latter existing only in late stages. In alloy 2, clusters, zones and S phases were also found. However the density of S phase is greater in alloy 2 compared to alloy 1 . DSC indicates that at $190^{\circ} \mathrm{C}$ clusters and zones have disappeared for both alloys and TEM also shows that $\mathrm{S}$ phase forms in both alloys with some limited $\Omega$ precipitation only in Alloy 1 . Equilibrium phase diagrams indicate that in Alloy 1 aged at $150-190^{\circ} \mathrm{C}$ the tetragonal $\theta$ phase is one of the equilibrium phases, but this phase was not detected in the present experiments. It is believed that $\Omega$ forms in preference to $\theta$ because it is partially coherent with the Al rich phase, and hence has a lower nucleation barrier.

Inhomogeneities in solute atom and vacancy concentrations may favour the appearance of two sorts of pre-precipitates, $\mathrm{Mg}$-rich clusters containing $\mathrm{Cu}$ atoms and vacancies, and $\mathrm{Cu}$-rich $\mathrm{GPB}$ zones containing some $\mathrm{Mg}$ atoms [12]. It is well established that the binding energy between $\mathrm{Mg}$ atoms and vacancies is higher than that between $\mathrm{Cu}$ atoms and vacancies [13]; the activation energy for $\mathrm{Mg}$ diffusion in aluminium is also lower than for $\mathrm{Cu}$ diffusion [14]. This suggests that $\mathrm{Mg}-\mathrm{Mg}$ clusters are the first to appear followed by $\mathrm{Cu}-\mathrm{Cu}$ and $\mathrm{Cu}-\mathrm{Mg}$ co-clusters. Lattice parameter measurements performed on a similar alloy during natural ageing also suggest that up to $1 \mathrm{~h}, \mathrm{Mg}$ atom clustering prevails and that at longer times mainly $\mathrm{Cu}$ atom clustering occurs [12]. Therefore, it is not surprising that in our specimens (aged $12 \mathrm{hrs}$ at $150^{\circ} \mathrm{C}$ ), most of clusters are Cu-rich (Table 2). Silcock [2] proposed that these zones formed along the $\langle 100>\alpha$ directions as small cylinders estimated to be 1-2 $\mathrm{nm}$ in diameter, and with lengths ranging from 4 to more than $8 \mathrm{~nm}$. Charai et al. 
[12] have found the $\mathrm{Cu}$-rich $\mathrm{GPB}$ zones at $200^{\circ} \mathrm{C}$ with a width about $5 \mathrm{~nm}$, which contains some $\mathrm{Mg}$ atoms in similar alloys. These descriptions fit with the small plate-like precipitates/zones rich in copper observed by 3DAP in both alloys.

In terms of microstructure-strength relations the present results indicate that peak strength during artificial ageing is due to $\mathrm{S}$ precipitation. Strengthening during the early stages (less than $24 \mathrm{~h}$ ) of ageing at $150^{\circ} \mathrm{C}$ is mainly caused by clusters and zones. On continued ageing at $150^{\circ} \mathrm{C}$ strengthening due to $\mathrm{S}$ phases becomes progressively more important, whilst clusters and zones dissolve.

\section{Conclusions}

Extensive experimental work by HV, DSC, TEM and 3DAP analysis has been conducted on a Al$1.2 \mathrm{Cu}-0.5 \mathrm{Mg}$ and a $\mathrm{Al}-1.2 \mathrm{Cu}-1.2 \mathrm{Mg}$ (at.\%) alloy at 150 and $190^{\circ} \mathrm{C}$ after solution treatment and stretching. During ageing at $150^{\circ} \mathrm{C}$ both alloys contain clusters, zones and $\mathrm{S}$ phase, but more $\mathrm{S}$ phase forms in the alloy with higher $\mathrm{Mg}$ content. For both alloys the precipitation hardening at $150^{\circ} \mathrm{C}$ is mostly dominated by the formation of these solute clusters and zones at early stages of ageing (less than 24h) and by the formation of $\mathrm{S}$ phase at the later stage of ageing. DSC indicates that for both alloys at $190^{\circ} \mathrm{C}$ clusters and zones have disappeared and TEM shows that S phase forms, which dominates the hardening response. In the alloy with the lower $\mathrm{Mg}$ content also some limited $\Omega$ precipitation occurs at $190^{\circ} \mathrm{C}$.

\section{Acknowledgements}

The authors would like to acknowledge the financial support from EPSRC, QinetiQ and Airbus UK.

\section{References}

1 T. Takahashi and T.J. Sato, Jpn, Inst. Light Metals, Vol. 35 (1985) 41-49.

2 J.M. Silcock, J. Inst. Met. Vol. 89 (1960-1961) 203-210.

3 S.P. Ringer, T. Sakurai and I.J. Polmear, Acta Mater. Vol. 45 (1997) 3731-3744.

4 S.P. Ringer, S.K. Caraher and I.J. Polmear, Scripta Met. Vol. 39 (1998) 1559-1567.

5 A.-M. Zahra, C.Y. Zahra, C. Alfonso and A. Charai, Scripta Met. Vol. 39 (1998) 1553-1958.

6 M.J. Starink, I. Sinclair, N. Gao, N. Kamp, P.J. Gregson, P.D. Pitcher, A. Levers and S. Gardiner, in the present proceedings.

7 M.J. Starink, P. Wang, I. Sinclair and P.J. Gregson, Acta Mater. Vol. 47 (1999) 3855-3868.

8 N. Gao, L. Davin, S. Wang, A. Cerezo and M.J. Starink, to be published, 2002.

9 A.K. Jena, A.K. Gupta and M.C. Chaturvedi, Acta Mater. Vol. 37 (1989) 885-895.

10 A. Luo, D.J. Lloyd, A. Gupta and W.V. Youdelis, Acta Mater. Vol. 41 (1993) 769-776.

11 D. Vaumousse and A. Cerezo, to be published in Ultramicroscopy.

12 A. Charai, T. Walther, C. Alfonso, A.-M. Zahra and C.Y. Zahra, Acta Mater, Vol. 48 (2000) 2751-2764.

13 S. Ozbilen and H.M. Flower, Acta Mater. Vol. 37 (1989) 2993-3000.

14 A.-M. Zahra, C.Y. Zahra, W. Lacom and K. Spiradek, Proc. Int. Conf. On Light Metals, Amsterdam, ASM International, (1990) 633-639. 